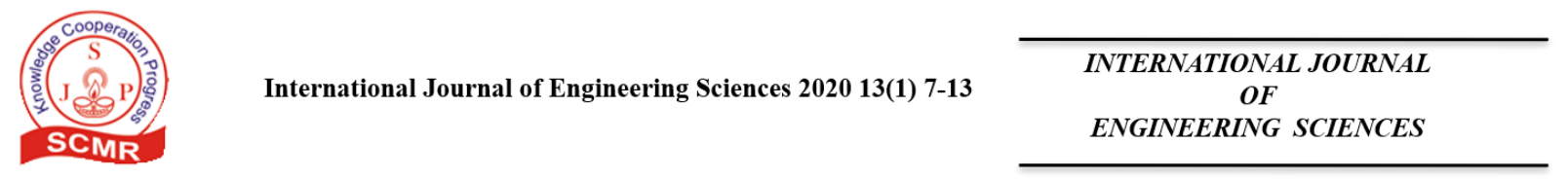

\title{
Regional Trends of Sea Level Rise along the Coast of Bangladesh
}

\author{
Naila Matin, G. M. Jahid Hasan*, Myisha Ahmad \\ Department of Civil Engineering, \\ Military Institute of Science and Technology, Dhaka, Bangladesh
}

(Received 18 June 2018, accepted 2 January 2020)

Doi: https://doi.org/10.36224/ijes.130102

\begin{abstract}
Bangladesh is becoming increasingly vulnerable to the growing threat of climate change induced sea level rise. Considering the potential severe impacts that sea level rise will have on the coastal population and the country's economy, it has become very important to know about the regional trends of changing sea levels along the coastlands of Bangladesh. The present study attempted to portray a representative scenario of sea level rise in the coastal regions of Bangladesh. Historic tide gauge records, ranging from 20 to 45 years, were used to determine reliable trends at multiple locations along the coast. Linear regression method was applied to derive the changing trend of annual high, mean and low tidal water levels. The location-specific trends of sea level rise determined in this study can be helpful to planners and policy makers to combat the emerging threat of SLR in a more efficient manner.
\end{abstract}

Keywords: Sea level rise, tidal water level, trend analysis, linear regression, Bangladesh

\section{Introduction}

Sea level rise (SLR) is slowly but surely, becoming one of the biggest threats to the coastlands of Bangladesh. Geographic location, flat topography and low elevations in the coastal regions play an important role in its high vulnerability to sea level change. Moreover, the coastal regions of Bangladesh are densely populated, with high poverty and heavy reliance for livelihood on natural resource bases of coastal ecosystems, and these poor communities are the most susceptible to rising sea levels. By 2050 it is predicted that Bangladesh's population at risk of SLR will go up to 27 million [1]. It is therefore very important to know the regional trends of SLR in Bangladesh. Intergovernmental Panel on Climate Change (IPCC) has previously projected many SLR trends, but only in a global scale. A few other previous studies documented SLR along the Bangladesh coast in broad-scale perspectives [2,3]. For effective planning and managing of the coastal zones, knowledge of location-specific trends of sea level change is an absolute necessity. The present study aimed to achieve this by determining small- scale regional trends of sea level change along the entire coast of Bangladesh, through analyzing historic tidal water levels. Tide gauge data have been widely used around the world in monitoring sea level change and making future projections [4,5], as understanding past sea levels is crucial for the analysis of current and future changes. SLR trends estimated in this study can serve as a general guideline in formulating regional policies and strategies, to address the potential severe impacts of SLR on the coastlands of Bangladesh. 


\section{Study Area}

The coastal region of Bangladesh was the main focus of the present study. The coastal zones cover almost a third of the total landmass of Bangladesh, with an area of approximately 47,201 $\mathrm{km}^{2}$ [6]. Three distinct geo-morphological zones have been identified in these coastlands: Ganges Tidal Plain (western zone), Meghna Deltaic Plain (central zone) and Chittagong Coastal Plain (eastern zone) [7], as shown in Fig. 1. A total of 19 districts constitute the exposed and interior coast of Bangladesh. In this study, SLR trends were determined in each geomorphological zone using multiple tide gauge station records, that extended from near the open sea to the most landwards locations of the coastal region.

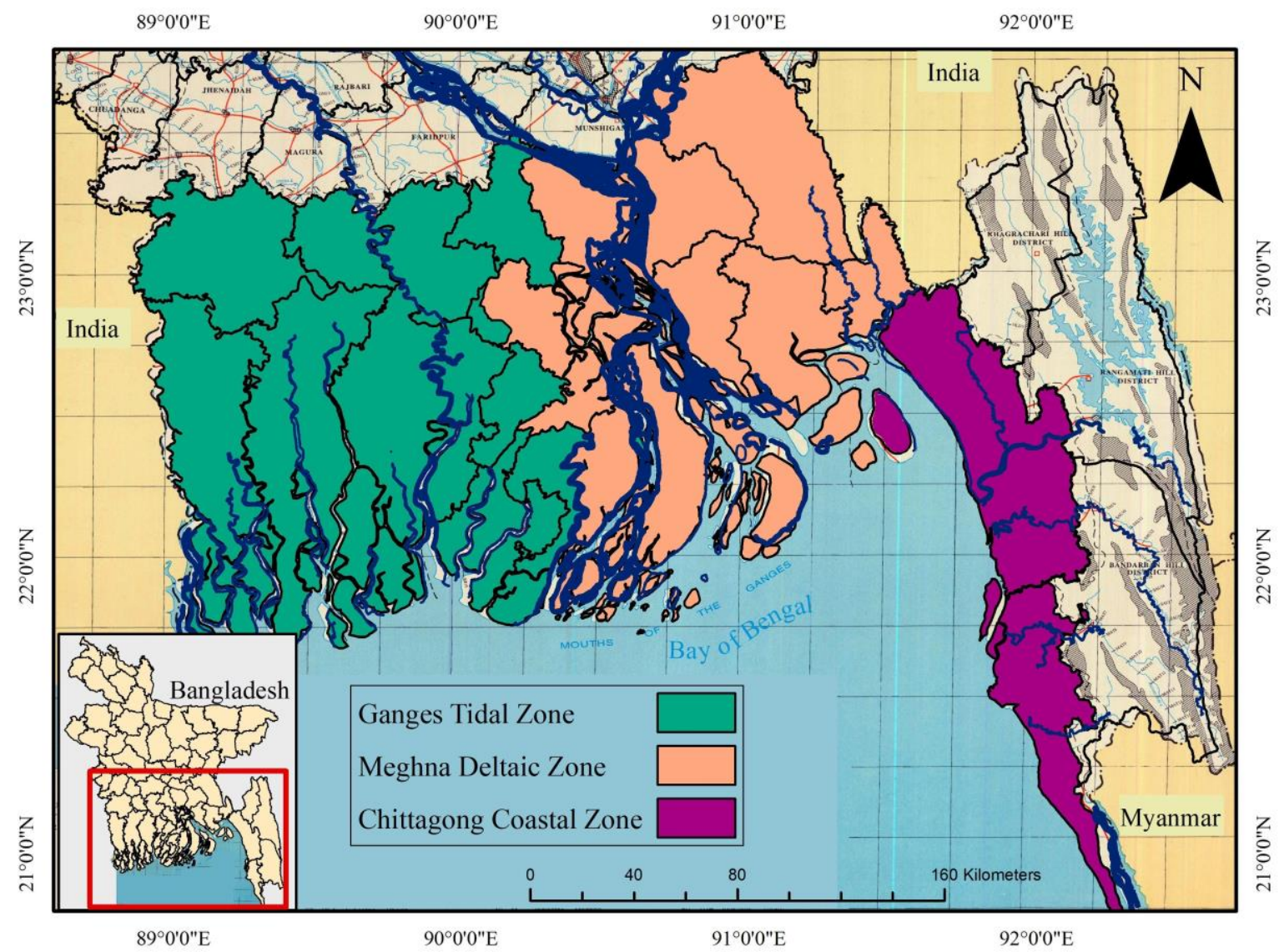

Figure 1: Coastal zones of Bangladesh based on geo-morphological features

\section{Methodology}

\subsection{Collection of Tide records}

Time series records of tidal water level variations were collected at the selected stations, for periods ranging from 20 years to as far as 45 years. Water level data in Bangladesh is primarily recorded and maintained by the Bangladesh Water Development Board (BWDB), which is responsible for about 127 tidal and 18 non-tidal water level stations near the coast, and also Bangladesh Inland Water Transport Authority (BIWTA) with 38 operational stations within the coastal region. From these stations, 10 stations were selected, as shown in Fig. 2, located within 
the interior and exterior coast of Bangladesh. The selected stations also covered the three major geo-morphological zones of the country. The stations were selected in such a way that, the regional variations of SLR could be observed spatially, covering the entire coast of Bangladesh.

\subsection{Data processing}

Raw tidal records were collected from BWDB in the form of daily high and low tide data, and from BIWTA as hourly data. The hourly tide data were converted to daily high and low water level data. For the estimation of mean tidal level, the daily high and low water levels were considered. Annual or yearly average water level data were then determined from the daily high, mean and low tide data. Consistency and continuity checks were also performed on these

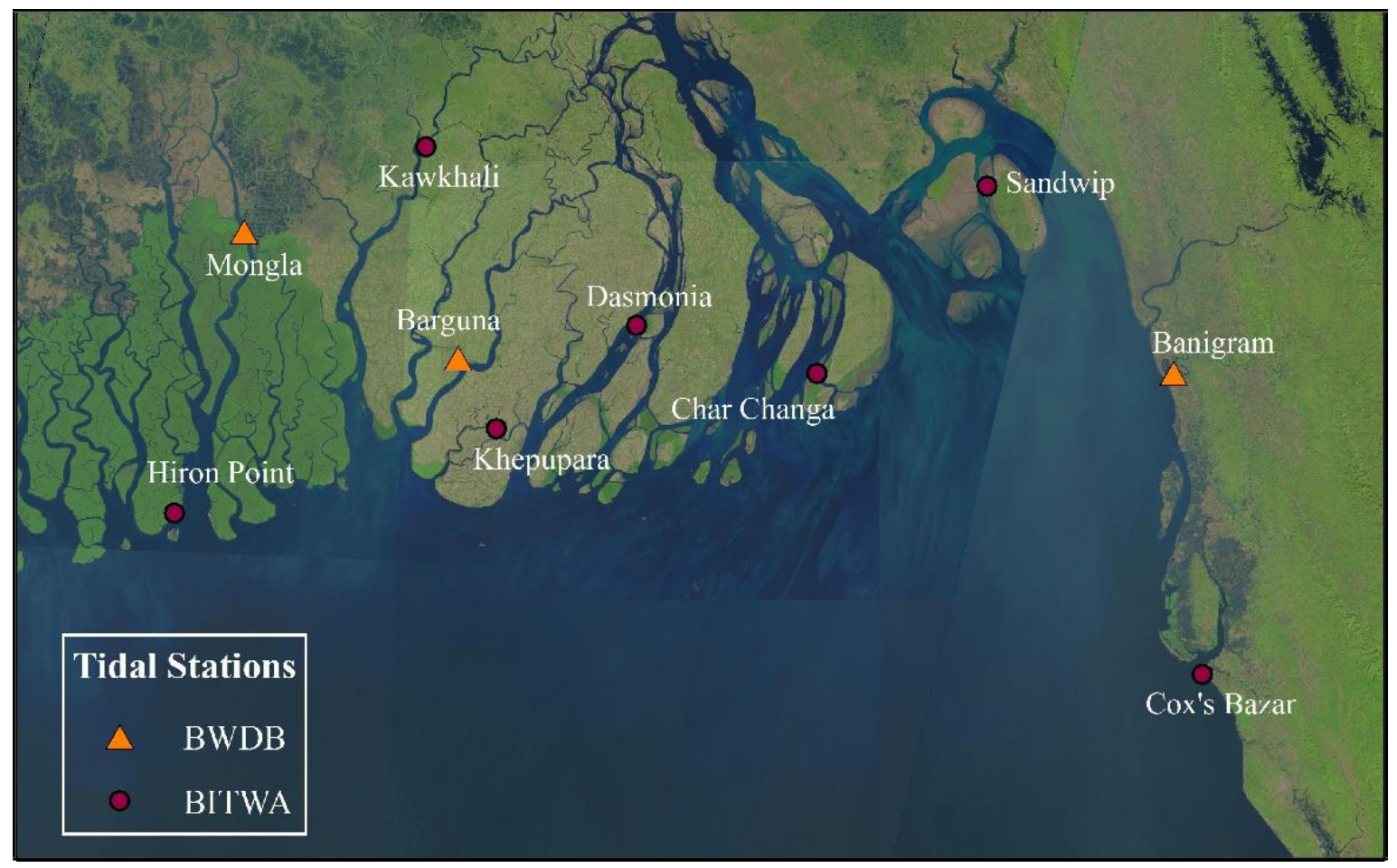

Figure 2: Selected tide gauge stations along the coast of Bangladesh

dataset. While checking consistency of the data, spikes and aberrant, unrealistic data were discarded and these data points were removed manually.

\subsection{Trend Analysis}

In this study linear regression method was adopted, which is a widely popular trend analysis approach for predictive purposes. A basic form of equation with one dependent variable (water level) and one independent variable (year) was assumed for analysis, as shown below:

$$
y=b * x+a
$$

where, $y=$ estimated dependent variable (i.e. water level)

$b=$ slope of the equation (i.e. rate of change)

$x=$ independent variable (i.e. time)

$a=$ constant 
For each of the selected tide gauge stations, individual correlation between water level and time was thus established. Finally, the coefficient of determination $\left(r^{2}\right)$ was estimated to check the goodness-of-fit of the regression relationships.

\section{Results and discussion}

Trends of annual high tide, low tide and mean tide level along the Bangladesh coast were determined in this study through linear regression method, using Equation (1). The results of trend analysis of mean tidal water level are given in Table 1. The coefficients: slope (' $b$ ') and constant (' $a$ ') describes the linear relationship of change in water level with time. From the values of coefficient of determination $\left(r^{2}\right)$, it can be seen that although a few stations showed satisfactory correlation, at many other stations data points deviated much from the regression

Table 1. Mean annual tidal water level trend at selected locations in the coastal region of Bangladesh

\begin{tabular}{|c|c|c|c|c|c|c|c|}
\hline \multirow{2}{*}{$\begin{array}{l}\text { Coastal } \\
\text { Zone }\end{array}$} & \multirow[t]{2}{*}{ Stations } & \multirow[t]{2}{*}{ Analysis Period } & \multicolumn{2}{|c|}{ Coefficient $^{*}$} & \multirow[t]{2}{*}{$\mathbf{r}^{2}$} & \multirow[t]{2}{*}{ Trend } & \multirow{2}{*}{$\begin{array}{c}\text { Rise } \\
\text { (mm/year) }\end{array}$} \\
\hline & & & $\mathrm{b}$ & $\mathrm{a}$ & & & \\
\hline \multirow{4}{*}{$\begin{array}{c}\text { Ganges } \\
\text { Tidal } \\
\text { Floodplain }\end{array}$} & Mongla & $\begin{array}{c}\text { 1968-2000, 2005-2016 } \\
\text { (45 years) }\end{array}$ & 7.2 & -13753 & 0.2971 & Increasing & 7.2 \\
\hline & Hiron Point & $1977-2003$ (27 years) & 4.6 & - 7418.4 & 0.2911 & Increasing & 4.6 \\
\hline & Barguna & $\begin{array}{c}\text { 1990-2003, 2006-2016 } \\
\text { (25 years) }\end{array}$ & 8.6 & -16148 & 0.3513 & Increasing & 8.6 \\
\hline & Kawkhali & $1987-2011(25$ years $)$ & 5.0 & -8870.5 & 0.1795 & Increasing & 5.0 \\
\hline \multirow{3}{*}{$\begin{array}{l}\text { Meghna } \\
\text { Estuarine } \\
\text { Floodplain }\end{array}$} & Khepupara & $1987-2015$ (29 years) & 3.3 & -4226.5 & 0.1124 & Increasing & 3.3 \\
\hline & Dasmonia & $1987-2011$ (25 years) & 5.6 & -9830.9 & 0.4553 & Increasing & 5.6 \\
\hline & Charchenga & 1987-2011 (25 years) & 6.6 & -10975 & 0.3061 & Increasing & 6.6 \\
\hline \multirow{3}{*}{$\begin{array}{c}\text { Chittagong } \\
\text { Coastal } \\
\text { Plain }\end{array}$} & Sandwip & $1996-2015$ (20 years) & 10.1 & -16908 & 0.1053 & Increasing & 10.1 \\
\hline & Banigram & $1985-2007$ (23 years) & 6.2 & -11132 & 0.0549 & Increasing & 6.2 \\
\hline & Cox's Bazar & $1983-2011$ (29 years) & 4.8 & -7470.1 & 0.1337 & Increasing & 4.8 \\
\hline
\end{tabular}

line. This is not unusual because the various factors causing changes in sea level, seldom contribute in a linear manner and so a perfect linear relationship can hardly exist. Also, SLR has become much more significant in recent years than in the past, causing an abrupt change in the historic trend. The trends determined in this study are thus approximate and can help recognize the areas where sea levels are rapidly changing and estimate a future scenario.

The change in sea levels showed considerable variation in different places along the coastline. Water level trends of various stages (high, mean and low tide) are showed in Fig. 3 (a), (b), (c) (one from each coastal zone). Fig. 3(d) illustrates the trends in all selected stations in a comprehensive graphical form. An older previous study [2], conducted almost 20 years ago, determined the trends of SLR at only three stations, one in each coastal zone. Results of that study showed a rise of $4 \mathrm{~mm} /$ year at Hiron Point (western zone), $6 \mathrm{~mm} /$ year at Charchenga (central zone) and $7.8 \mathrm{~mm} /$ year at Cox's Bazar (eastern zone). The observed trends of the western and central zone are comparable to the average trends found in the present study. In the eastern zone however, the determined trends of the two studies differ substantially. This may be due to the difference in time periods, considered in the two studies. In the previous study, trend at Cox's Bazar was observed for the period 1977-1998, whereas the present study considered 
more recent and up to date data (1983-2011). The sea level changes observed in different coastal zones are summarized in the following sub-sections.

\subsection{Ganges Tidal Floodplain}

All the stations in this zone exhibited an increasing trend of mean sea level. The magnitude of increase in sea level appeared to be inversely proportional to the distance from the open sea. The station farthest away from sea and towards the mainland is Kawkhali, and the mean sea level change observed there is $5 \mathrm{~mm} /$ year. The change gradually increases in magnitude at stations located closer to coast, finally becoming $8.6 \mathrm{~mm} /$ year at Barguna. At Hiron Point, the SLR rate $(4.6 \mathrm{~mm} / \mathrm{year})$ is found not very high, even though the station is located close to the open sea. The trend of high-tide is positive at every station, and the magnitude of SLR is greater
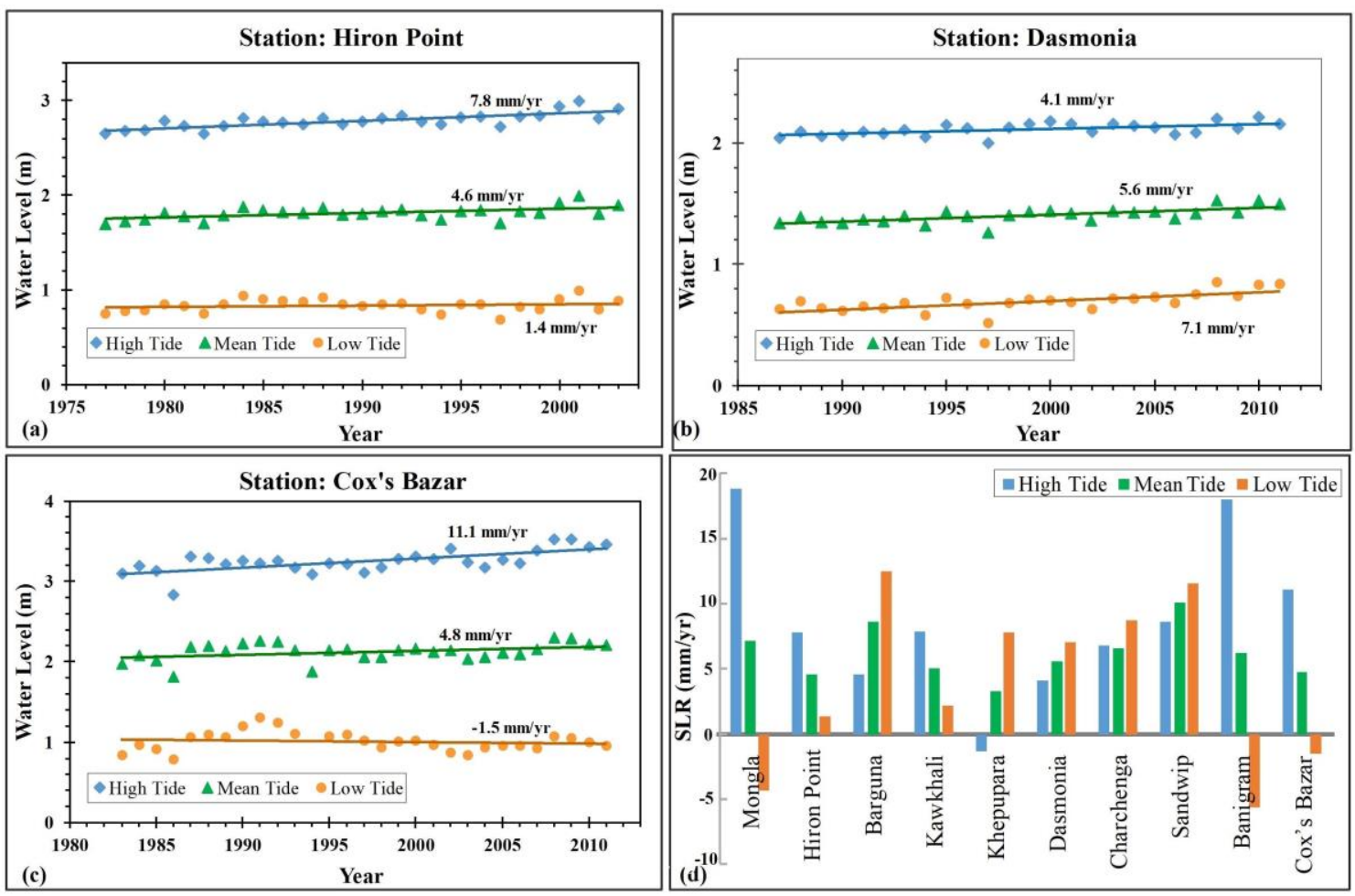

Figure 3: Tidal water level trends at (a) Hiron Point (b) Dasmonia (c) Cox’s Bazar (d) selected stations

at landward stations than the mean tidal trend. The trend of low-tide stage is found more irregular, with negative change at Mongla station. This could be attributed to the drastic decrease of dry-season flow in the Gorai-Madhumati rivers, caused mainly by the construction of Farakka barrage in 1975 across the Ganges river [8] and also excessive abstraction of river and groundwater for dry-season irrigation. Again seaward locations like Barguna seemed unaffected by this and showed high increasing rate of sea level, even during low-tide stage.

\subsection{Meghna Estuarine Floodplain}

Increasing trend of mean tidal level is observed at all the stations of this region. Average rate of 
SLR at Dasmonia and Charchenga is about $6 \mathrm{~mm} / y e a r$. The confluence effect at the estuary mouth could be responsible for such higher rates. At Khepupara, SLR is found relatively low, compared to the other stations in this region. This station being located offshore ward, in a small tidal creek and having limited connection with the sea, may be the reasons behind this low rate. At the other stations similar trends to the mean sea level is observed also for the hightide and low-tide stages.

\subsection{Chittagong Coastal Plain}

The stations in this region also showed an increasing trend of mean sea level. However, much variation is observed in the trend, amongst the different stations in this zone. At Sandwip station, the rate is observed $10.1 \mathrm{~mm} /$ year, at Banigram it is found $6.2 \mathrm{~mm} /$ year and at Cox's Bazar the rate is found to be $4.8 \mathrm{~mm} /$ year. Variation in the degree of exposure to the sea at different stations could be responsible for this fluctuation in rate. Again, proximity of the station to the Meghna estuary and Sandwip channel, could have contributed to the high SLR rate at Sandwip station. There is also wide fluctuation between high-tide and low-tide water levels in this region. Although both Cox's Bazar and Banigram show increasing trend during high-tide, notable negative rates can be observed at these stations during low-tide. The gentle slope of land in this zone is perhaps the likely cause of such variation. Compared to other regions, this zone appeared to have more irregular patterns in water level, and data points deviated substantially from the regression line.

\section{Conclusion}

This study attempted to visualize the scenario of sea level rise along the coast of Bangladesh and establish approximate rates of change, through extensive analysis of historical dataset of observed tidal water levels. The change in sea level varied considerably along the coast spatially, particularly depending on the degree of exposure or proximity of the station to the open sea. Some local factors like land subsidence, sedimentation, wind circulation, polderization etc., could have also influenced the regional estimation of SLR. At most of the stations considered in this study, an increasing trend of annual high, mean and low-tide water level is observed, with only a few exceptions. In many locations rise in sea level appears to have an alarmingly large rate and this is likely to intensify even more with time. Results of this study can be helpful to policy makers and planners in developing functional and more adaptable coastal management policies, with considerations of the regional trends of SLR.

\section{Acknowledgement}

The authors would like to thank the Military Institute of Science and Technology (MIST) for their help in materializing this study. Their support is gratefully acknowledged.

\section{References}

[1] "Intergovernmental Panel on Climate Change (IPCC)", IPCC fifth assessment synthesis report on climate change, 2014

[2] O. P. Singh, "Spatial variation of sea level trend along the Bangladesh coast", Marine Geodesy, 25(3), 205-212, 2002 
[3] R. A. Warrick and Q. K. Ahmad eds., "The implications of climate and sea-level change for Bangladesh". Kluwer, Dordrech, 1-415, 1996

[4] B C Douglas, "Global sea rise: a redetermination". Surveys in Geophysics, 18(2-3), 279-292, 1997

[5] P L Woodworth, W R Gehrels and R S Nerem, "Nineteenth and twentieth century changes in sea level”. Oceanography, 24(2), 80-93, 2011

[6] WARPO, "Delineation of the coastal zone". Program Development Office for Integrated Coastal Zone Management Plan (PDO-ICZMP). Water Resources Planning Organization (WARPO), Ministry of Water Resources, Government of the People's Republic of Bangladesh, Dhaka, 2003

[7] M F Karim, M. F. \& N Mimura, "Impacts of climate change and sea-level rise on cyclonic storm surge floods in Bangladesh", Global Environmental Change, 18(3), 490-500, 2008

[8] S N Islam, and A Gnauck, "Water shortage in the Gorai river basin and damage of mangrove wetland ecosystems in Sundarbans, Bangladesh". 3rd International Conference on Water \& Food Management, 8-10, 2011 